\title{
Uridine modulates monoclonal antibody charge heterogeneity in Chinese hamster ovary cell fed-batch cultures
}

\author{
Huijie Niu, Jiaqi Wang, Mengjuan Liu, Miaomiao Chai, Liang Zhao, Xuping Liu, Li Fan* and Wen-Song Tan
}

\begin{abstract}
Background: Charge heterogeneity is one of the most critical quality attributes of antibodies, which has strong influence on drug's biological activity and safety. Finding out the key components that affecting charge variants is of great significance for establishing a competitive culture process. In this study, we first illustrated uridine's great impacts on antibody charge heterogeneity in $\mathrm{CHO}$ cell fed-batch cultures.

Results: Uridine was beneficial to cell growth and the maintenance of cell viability, which made IVCC increased by $50 \%$ and the final titer improved by $64 \%$. However, uridine had great influences on mAb's charge variants. In uridine added cultures, the acidic variant levels were about $9 \%$ lower than those in control cultures, while the basic variant levels were about $6 \%$ higher than those in control cultures. Further investigation found that the decrease of aggregates and glycated forms were responsible for the reduction of acidic variants. What's more, uridine decreased the lysine variant levels.

Conclusions: Uridine's addition to fed-batch promoted cell growth and the final titer, in the meanwhile, uridine decreased the acidic variants dramatically. Therefore, feeding uridine is an efficient way to control the generation of acidic charge variants in up-stream process. These findings provide new ideas and guidance for the control and optimization of antibody charge heterogeneity in culture process developments.
\end{abstract}

Keywords: Charge heterogeneity, Chinese hamster ovary cells, Medium components, Monoclonal antibody, Uridine

\section{Background}

Monoclonal antibodies (mAbs) produced by Chinese hamster ovary $(\mathrm{CHO})$ cells have been growing rapidly during the past two decades. The majority of the biopharmaceutical industry is currently using fed-batch cultures as a platform technology and $\mathrm{CHO}$ cells as host cells for mAb's production. CHO cells have excellent ability to support mAb's expressing, secreting, and post-translational modifications (PTMs) (Jayapal et al. 2007). Charge heterogeneity is an important kind of microheterogeneity caused by post-translational modifications and chemical degradations, which has significant influence on mAb's stability, pharmacokinetics, potency, and biological

\footnotetext{
*Correspondence: fanli@ecust.edu.cn

The State Key Laboratory of Bioreactor Engineering, East China University of Science and Technology, 130 Mei-Long Road, P. O. Box 309, Shanghai 200237, People's Republic of China
}

activities. Sialic acid in glycosylations (Khawli et al. 2010), deamidation (Haberger et al. 2014), reduction of disulfide bond (Dillon et al. 2008) and glycation (Wei et al. 2017) are main sources of acidic variants, while incomplete clipping of lysine residues (Luo et al. 2012), proline amidation (Kaschak et al. 2011), Met/Trp oxidation (Liu et al. 2008) and cyclization of N-terminal Gln (Brorson and Jia 2014) may cause basic variants. Therefore, mAb's charge heterogeneity is exhibited under one or several post-translational modifications. During cell culture process, changes such as scale, medium components, and process parameters may cause inconsistencies on charge heterogeneity.

Medium nutrient components, such as amino acids, vitamins, and metals ions, are very important for mAb's charge heterogeneity. Sodium butyrate showed increased basic charge variants of mAbs (Hong et al. 2014); basic 
amino acids Arg and Lys can increase levels of lysine variant due to product inhibition effect of Arg and Lys on basic carboxypeptidases (Zhang et al. 2015). Metal ions in medium have significant effects on Mab's charge heterogeneity. Lysine variants increased with the increasing of copper concentration and the decreasing of zinc concentration (Luo et al. 2012), and other investigation showed the higher copper concentration, the higher proline amidation levels were detected. It was found that the supplementation of bioflavonoid chemical family into culture media can reduce the acidic charge variants (Hossler et al. 2015).

Uridine is a kind of exogenous nucleoside added to medium, which is related with nucleotides de novo synthesis pathway. However, few reports have described the application of exogenous nucleoside addition for protein production processes especially for protein's quality. Chen et al. illustrated that hypoxanthine and thymidine can promote initial cell growth and volumetric production of $\mathrm{mAb}$ without effects on long-term stability of antibody-producing $\mathrm{CHO}$ cells (Chen et al. 2011). Deoxyuridine were observed to increase the $\mathrm{mAb}$ concentration to $5.5 \mathrm{~g} / \mathrm{L}$ compared with $3.3 \mathrm{~g} / \mathrm{L}$ of no addition of deoxyuridine, and there were no significant differences in the specific production rate (Takagi et al. 2017). In terms of mAb's quality, it was clarified that feeding of uridine, galactose and manganese chloride can increase the galactosylation level (Gramer et al. 2011).

Our research first illustrated uridine's great effects on mAb's charge heterogeneity in fed-batch culture of a Chinese hamster ovary cell line. We further investigated uridine's effects on PTMs including glycosylation, aggregation, glycation and lysine variant.

\section{Methods}

\section{Cell line and cell culture}

A $\mathrm{CHO}$ cell line which produce a chimeric anti-CD20 monoclonal antibody was used in this study (Sun et al. 2013). The basal medium was a mix of two chemically defined medium purchased from Sigma-Aldrich. The feed medium 1 (FM 1) was an in-house developed animal component-free medium without uridine, while feed medium 2 (FM 2) was added $40 \mathrm{mM}$ uridine based on FM 1. Seed cells were generated in $500-\mathrm{mL}$ shake flasks (Corning, NY, USA) in an incubator (Thermo Fisher, OH, USA) at $5 \%$ carbon dioxide and $37{ }^{\circ} \mathrm{C}$. Seed cells were inoculated at $1.5 \times 10^{6}$ cells $/ \mathrm{mL}$ into $50-\mathrm{mL}$ tubular spin using fresh basal medium in a humidified tube spin incubator supplied with $5 \% \mathrm{CO}_{2}$ at $37{ }^{\circ} \mathrm{C}$. The feed medium was added daily at $1.2 \%(\mathrm{v} / \mathrm{v})$ from day 1 , respectively. Sampling was performed to determine viable cell density and the supernatant was kept at $-80{ }^{\circ} \mathrm{C}$ for further analysis.

\section{Routine analytical methods}

Sampling was performed to determine viable cell density and the dead cells were distinguished using Trypan Blue dye exclusion method. The mAb concentration in supernatant was determined by Protein A HPLC assay. The specific $\mathrm{mAb}$ production rate $\left(q_{\mathrm{mAb}}\right)$ was calculated from a plot of the cumulative $\mathrm{mAb}$ concentration against the integral of viable cell concentration with time (IVCC) (Yoon et al. 2003).

\section{Protein A HPLC assay}

The mAb concentration was measured using a POROS ${ }^{\circledR}$ A $20 \mu \mathrm{m}(2.1 \times 30 \mathrm{~mm}$, Thermo $)$ column coupled with Waters (Milford, MA) Alliance 1525 HPLC and monitored by a UV detector at $280 \mathrm{~nm}$. Mobile phase A was phosphate buffered saline (PBS); while mobile phase B contained $150 \mathrm{mM}$ sodium chloride, $\mathrm{pH}$ 2.0. The column was equilibrated by $100 \% \mathrm{~A}$, and shifted to $100 \% \mathrm{~B}$ to elute the sample.

\section{Purification of cell culture supernatants}

The mAbs in harvest culture supernatants were purified using a 1-mL protein A affinity column (GE Healthcare). After loading the sample, the column was equilibrated by buffer A (20 mM Tris- $\mathrm{HCl}, 100 \mathrm{mM} \mathrm{NaCl}, \mathrm{pH} 7.4)$ and washed by buffer B $(20 \mathrm{mM}$ Tris- $\mathrm{HCl}, 100 \mathrm{mM} \mathrm{NaCl}$, $\mathrm{pH}$ 7.4); then the sample was eluted by citric acid and adjusted $\mathrm{pH}$ to neutral using $2 \mathrm{M}$ Tris- $\mathrm{HCl}(\mathrm{pH} 8.0)$. All the HPLC analysis below used mAb samples after purification.

\section{Weak cation exchange chromatography (WCX) analysis}

WCX was conducted to determine the charge variant contents of mAbs. About $50 \mu \mathrm{g}$ purified mAb was injected into an Agilent 1260 HPLC system coupled with a ProPac ${ }^{\circledR}$ WCX-10 column, $4 \mathrm{~mm} \times 250 \mathrm{~mm}$ (Dionex, CA, USA). Mobile phase A contained $20 \mathrm{mM} 2$-( $N$-morpholino)ethanesulfonic acid (MES), $\mathrm{pH} 6.5$, and mobile phase B contained $150 \mathrm{mM}$ sodium chloride, $20 \mathrm{mM}$ MES, $\mathrm{pH}$ 6.5. The column temperature was set at $30{ }^{\circ} \mathrm{C}$. A linear gradient elution from 30 to $75 \% \mathrm{~B}$ in 20 min was used at $0.9 \mathrm{~mL} / \mathrm{min}$ to separate $\mathrm{mAb}$ charge variant with a UV detector at $280 \mathrm{~nm}$. The charge variant contents were determined by calculating the percentage of total peak area.

\section{$\mathrm{N}$-Glycan profile analysis}

The oligosaccharide isolation and labeling were performed as described previously (Gramer et al. 2011). In brief, $N$-glycans was released by $N$-glycosidase $\mathrm{F}$ (Prozyme, Hayward, CA) digest from purified sample, and the released glycans were labeled with the 
fluorophore 2-aminobenzamide (2AB; Prozyme). $2 \mathrm{AB}$ labeled glycans were bound on a TOSOH TSKgel Amide$80(150 \mathrm{~mm} \times 4.6 \mathrm{~mm})$ column equilibrated in acetonitrile and eluted with a gradient of $50 \mathrm{mM}$ ammonium formate, $\mathrm{pH}$ 4.4. It was detected on a Waters (Milford, MA) Alliance 1525 HPLC with a Multi $\lambda$ fluorescence detector 2475 (excitation at $330 \mathrm{~nm}$, emission at $420 \mathrm{~nm}$ ). The amount of each structure is expressed as the percentage of total peak area. Overall galactosylation (Siemiatkoski et al. 2006) and fucosylation percentages of the complex structures were calculated as follows:

$$
\begin{aligned}
& \text { Galactosylation (\%) } \\
& =\frac{\mathrm{G} 1+\mathrm{G} 1 \mathrm{~F}+2 \times \mathrm{G} 2+2 \times \mathrm{G} 2 \mathrm{~F}}{2(\mathrm{G} 0+\mathrm{G} 0 \mathrm{~F}+\mathrm{Man} 5+\mathrm{G} 1+\mathrm{G} 1 \mathrm{~F}+\mathrm{G} 2+\mathrm{G} 2 \mathrm{~F})} \\
& \quad \times 100 \%
\end{aligned}
$$

Fucosylation (\%)

$$
=\frac{\mathrm{G} 0 \mathrm{~F}+\mathrm{G} 1 \mathrm{~F}+\mathrm{G} 2 \mathrm{~F}}{\mathrm{G} 0+\mathrm{G} 0 \mathrm{~F}+\mathrm{Man} 5+\mathrm{G} 1+\mathrm{G} 1 \mathrm{~F}+\mathrm{G} 2+\mathrm{G} 2 \mathrm{~F}}
$$

G0, G0F, G1, G1F, G2, G2F and Man5 are main glycan forms of $\mathrm{mAb}$.

\section{Size exclusion chromatography}

The aggregation level of purified $\mathrm{mAb}$ was determined by size exclusion chromatography (SEC) using a TSK-Gel G3000SWX column, $7.8 \mathrm{~mm} \times 300 \mathrm{~mm}(\mathrm{TOSOH}$, Yamaguchi, Japan) at room temperature on an Agilent 1260 HPLC system. Samples were eluted over $30 \mathrm{~min}$ with a $0.2 \mathrm{M}$ sodium chloride and $20 \mathrm{mM}$ potassium phosphate, $\mathrm{pH} 7.4$ and monitored by a UV detector at $280 \mathrm{~nm}$. The flow rate was $0.5 \mathrm{~mL} / \mathrm{min}$. The level of aggregation was expressed as the relative percentage of peak areas.

\section{Boronate affinity chromatography}

The glycated levels of charge variants were determined by boronate affinity chromatography (BAC) (Wei et al. 2017). The samples were analyzed on an Agilent 1260 HPLC system using a TSK-Gel boronate-5PW column, $7.5 \mathrm{~mm} \times 75 \mathrm{~mm}$ (TOSOH, Yamaguchi, Japan). The affinity-based separation was performed at room temperature with the flow rate at $1.0 \mathrm{~mL} / \mathrm{min}$. The mobile phases A was $100 \mathrm{mM}$ HEPES, $25 \mathrm{mM}$ Tris, $200 \mathrm{mM} \mathrm{NaCl}$, at $\mathrm{pH} 8.6$; and mobile phases $\mathrm{B}$ was added $500 \mathrm{mM}$ sorbitol based on mobile phase A. After sample injection, the non-glycated antibodies flowed through the column in mobile phase $\mathrm{A}$, and then the glycated antibodies were eluted from the resin in mobile phase B. The UV detector was set at $280 \mathrm{~nm}$ with an 8 -nm bandwidth. The glycation level was expressed as the relative percentage of peak areas.

\section{Results and discussion}

\section{Effect of uridine on cell growth and mAb production}

Fed-batch cultures in tubular spin were carried out for 14 days with $40 \mathrm{mM}$ uridine added to feed medium, while the control cultures were performed without uridine added. Feed medium was fed into culture fluid daily at $1.2 \%(\mathrm{v} / \mathrm{v})$ from day 1 , respectively, while the total uridine feed concentration was $6 \mathrm{mM}$. The effect of uridine on cell growth and $\mathrm{mAb}$ production are summarized in Fig. 1 and Table 1. Figure 1a showed viable cell density (VCD) with culture time, and Fig. $1 \mathrm{~b}$ represented the cell viability in two different culture processes. Uridine had significant beneficial effects on cell growth and maintaining. By feeding uridine at a total concentration of $6 \mathrm{mM}$, the process peak cell density can reach $15.9 \times 10^{6}$ cells/ $\mathrm{mL}$, representing a $31 \%$ increase compared with that of
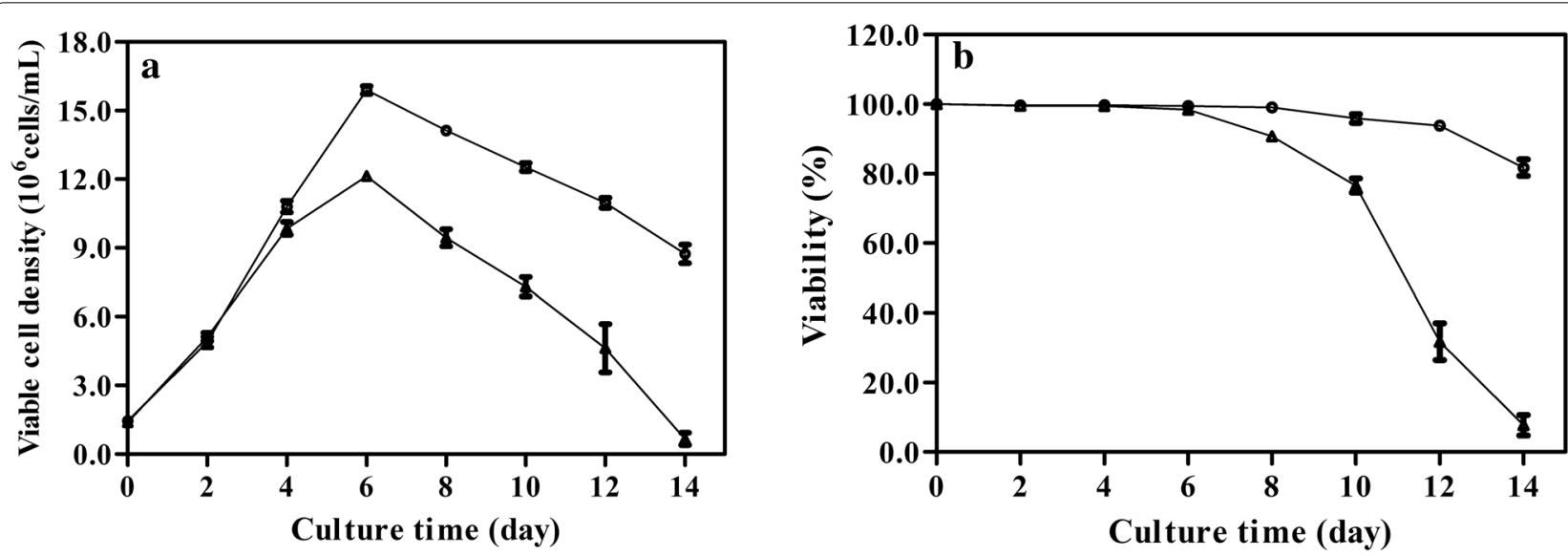

Fig. 1 Effects of addition of uridine on cell growth, and cell viability. a Viable cell density; $\mathbf{b}$ cell viability. Control cultures were performed without uridine feed (blank triangle); uridine was added to culture at a total concentration of $6 \mathrm{mM}$ (blank circle). The error bars indicate the standard deviations from three independent experiments 
Table 1 Effect of uridine on cell growth and $\mathrm{mAb}$ production

\begin{tabular}{|c|c|c|c|c|}
\hline $\begin{array}{l}\text { Cultures with different feed } \\
\text { medium }\end{array}$ & Peak VCD ( $\times 10^{6}$ cells $\left./ \mathrm{mL}\right)$ & IVCC ( $10^{9}$ cells day/L) & Mab concentration (g/L) & $q_{\mathrm{mAb}}\left[\mathrm{mg} /\left(10^{9}\right.\right.$ cells day $\left.)\right]$ \\
\hline Control & 12.13 & 98.98 & 2.25 & 22.72 \\
\hline Uridine added & $15.90^{* *}$ & $148.64 * *$ & $3.69 * *$ & 24.81 \\
\hline
\end{tabular}

IVCC integral of viable cell concentration with time, $q_{\mathrm{mAb}}$ specific mAb production

${ }^{*} p<0.05$ relative to control; ${ }^{* *} p<0.01$ relative to control

the control culture $\left(12.1 \times 10^{6}\right.$ cells $\left./ \mathrm{mL}\right)$. Cells in control culture declined rapidly since day 10 , causing the viability at day 14 dropped to $7 \%$ and IVCC was $98.98 \times 10^{9}$ cells day/L. When feeding uridine, cell maintenance was significantly improved. Cell viability remained high (>80\%) during 14 days, leading IVCC improved by $50 \%$. Uridine's positive effects on cell growth and maintenance led to a much higher final titer $(3.69 \mathrm{~g} / \mathrm{L})$ compared with control culture $(2.25 \mathrm{~g} / \mathrm{L}) . Q_{\mathrm{mAb}}$ also had a slight increase but is not significant.

\section{Effect of uridine on mAb charge heterogeneity}

As shown in Fig. 2a, great differences in acidic and basic charge variants were observed during culture process. In both cultures, acidic variants increased gradually with time extended. There was no significant difference at day 6 and day 8, but the acidic variants grown rapidly from day 10 and reached $28.9 \%$ at day 14 in control cultures. In uridine added culture, the increasing trend was quite declined so that acidic variant level maintained at a much lower level, which was $20.0 \%$ at day 14. The results indicated that feeding uridine has inhibitory effect on the generation of acidic variants.

The trend of basic variants was not consistent in two culture process (Fig. 2b). In control cultures, basic variants gradually decreased from day 8 and dropped to $22.6 \%$ day 14 . However, basic variants contents in uridine added cultures was $28.7 \%$ at day 14 , which almost remained unchanged from day 8 . The different trend made basic variants in uridine added cultures increased significantly $(p<0.01)$.

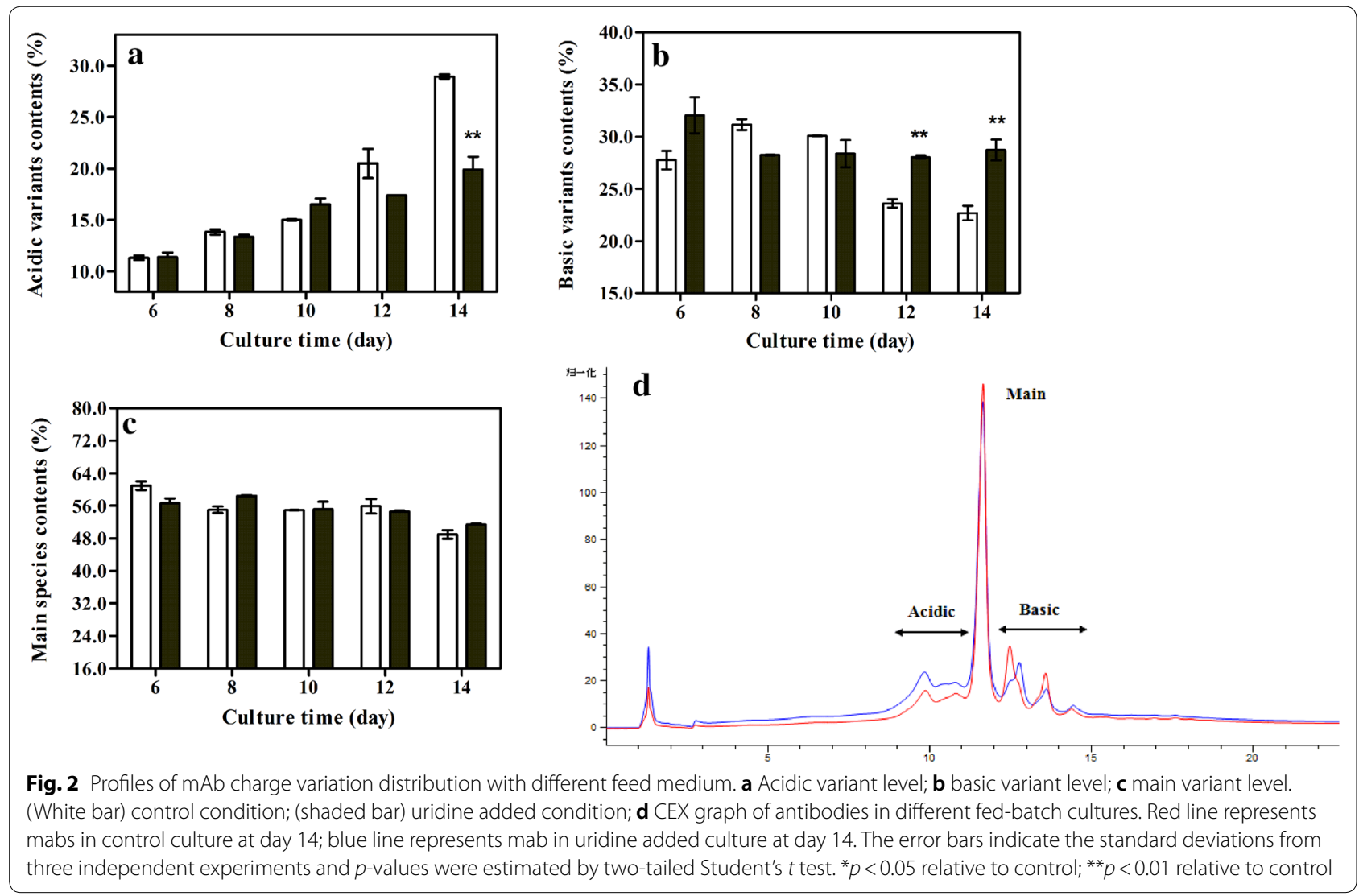


Main species is the major peak shown on CEX chromatogram, which is generally determined by the contents of acidic variants and basic variants of the mAb. As uridine's inhibitory effect on acidic variants and promotion effect on basic variants, main species content had a slight increase $(2.7 \%)$ by uridine feeding. Figure $2 \mathrm{~d}$ showed the CEX chromatograph of mAbs produced by two fed-batch cultures on day 14 .

\section{Effects of uridine on mAb's glycosylation, aggregation and glycation}

Charge heterogeneity of mAb was caused by various PTMs and degradation happened in cell culture process. We have known that uridine made acidic variants decreased and basic variants increased. In this part, we did further investigations on mAb's glycosylation, aggregation and glycation levels to discuss the reason why uridine made acidic variants decreased, and in next part we discussed uridine's effects on basic variants from the perspective of lysine variants.

Glycosylation is one of the most important post-translational modifications of monoclonal antibody, which plays a crucial role on pharmacokinetics, thermal stability, immunogenicity, and biological activity of drugs. Sialic acid is an acidic monosaccharide derivative that constitutes the end of sugar chain, which will cause the formation of acidic charge variants. It has also been reported that galactosylation change of mAb may lead to acidic charge variants, although the reason was not clear (Yan et al. 2009; Yang et al. 2014). The glycosylation was detected to consider its influence on charge variants. Figure 3 shows the contents of glycoforms under two fed-batch cultures at day 14. G0, G0F, and G1F were three major glycoforms of mAbs. The difference was mainly reflected on the GOF and Man5 glycoforms. The

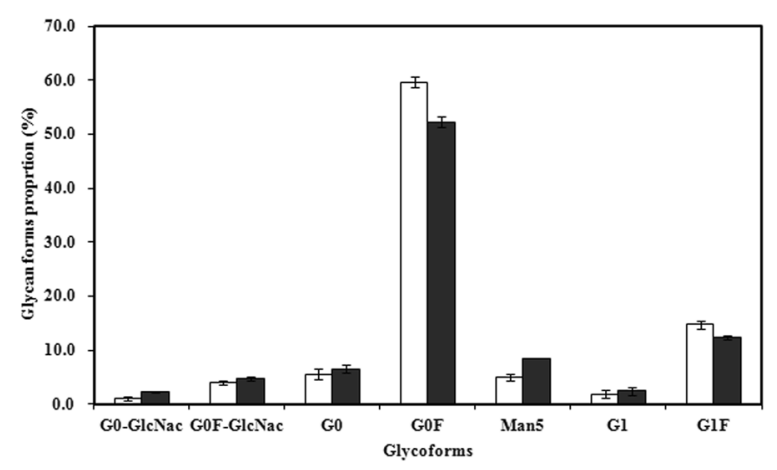

Fig. 3 Glycoform proportion of $m A b$ in two fed-batch cultures. (White bar) control condition; (shaded bar) uridine added condition. The error bars indicate the standard deviations from three independent experiments and p-values were estimated by two-tailed Student's t-test
Table 2 Galactosylation and fucosylation contents of antibody

\begin{tabular}{lll}
\hline & Galactosylation (\%) & Fucosylation (\%) \\
\hline Control & 8.0 & 78.4 \\
Uridine added & 7.4 & 69.3 \\
\hline
\end{tabular}

G0F content in control culture was 59.7\%, while the G0F content in uridine added culture decreased to $52.3 \%$. Man 5 content was $8.5 \%$ in uridine added culture, which increased about $70 \%$ compared with control culture. Galactosylation and Fucosylation levels can be calculated. Fucosylation level decreased from 78.4 to $69.3 \%$ by feeding uridine (Table 2). Galactose and fucose are neutral sugars, so they could not change net charge directly, but their influence on mAb's structure may change mAb's surface charge. The content of sialic acid was too low $(<1 \%)$, so not discussed here.

Aggregate is a kind of protein polymer formed by covalent bond or intermolecular force among antibody molecular. Aggregation happened in cell culture process may influence charge heterogeneity by changing antibody's surface charge characteristics. Therefore, the levels of aggregate in the antibody were detected by size exclusion chromatography. Aggregate level in uridine added culture was lower than that in control culture (Fig. 4a). Uridine reduced aggregates by $48 \%$ at day 14 . Aggregates' effect on charge variants is specific due to the different amino acid sequence and secondary structure of various antibody molecules. Some research found that aggregates in basic variants were more than that in acidic variants (Gandhi et al. 2012; Khawli et al. 2010; Zhang et al. 2011). However, our previous studies showed that acidic variants contained more aggregates than basic variants $(3.6 \%$ vs $0.3 \%$ ), which indicated that aggregates may relate with the formation of acidic charge variants in this cell line. Therefore, the reduction of aggregates may be one of the reasons why uridine made acidic variants inhibited.

Glycation of antibody is a kind of non-enzymatic reaction happened in the presence of reduced sugars. Glycation reaction will neutralize the positive charge on antibody surface, resulting in the generation of acidic variants. As can be seen from Fig. 4b, during fed-batch culture process, glycated level increased gradually. At day 14 , the glycated level was $25.0 \%$ and $19.3 \%$ in control culture and uridine added culture. Therefore, reduction of aggregates contents and glycated level attributed to the decreasing of acidic variants when feeding uridine.

Effect of uridine feeding on mAb's lysine variation

Lysine variation is a kind of basic variants caused by incomplete cleavage of $\mathrm{C}$-terminal lysine residues, which 

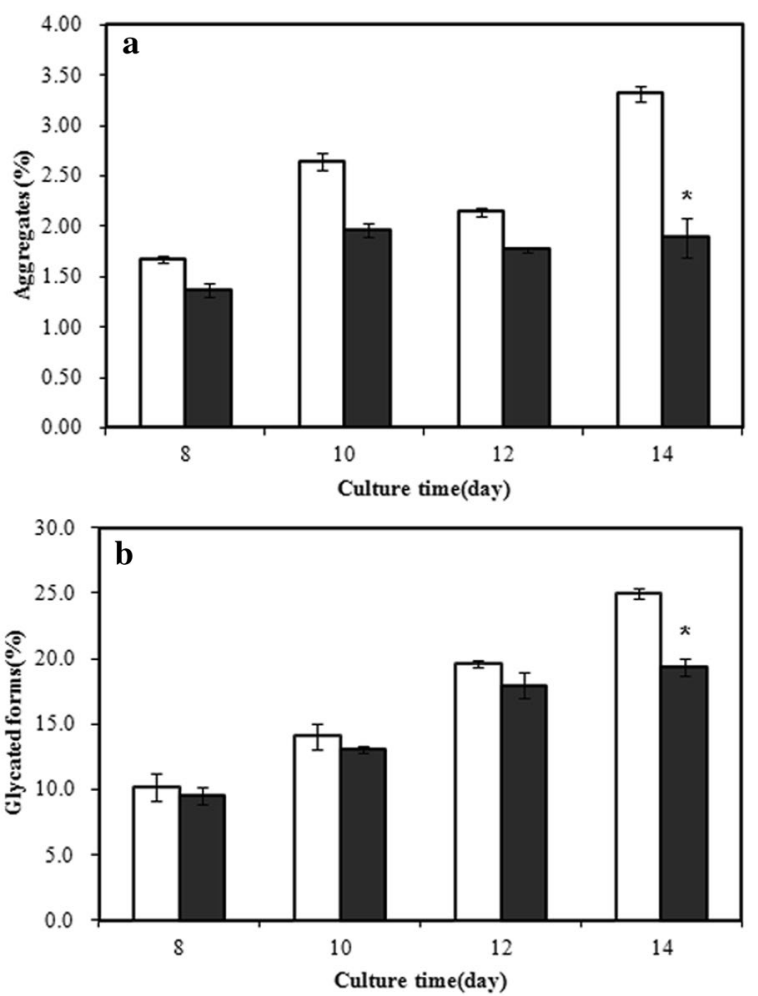

Fig. 4 Aggregate and glycated level during different culture process. a Aggregate level; b glycated level. (White bar) control condition; (shaded bar) uridine added condition. The error bars indicate the standard deviations from three independent experiments and $p$-values were estimated by two-tailed Student's $t$-test. ${ }^{*} p<0.05$ relative to control

can be cleaved by carboxypeptidases in vivo and vitro. Lysine variation was further investigated to determine the sources of basic variants. As can be seen in Fig. 5a, lysine variant contents in uridine added culture were about $50 \%$ of those in control culture from day 8 to day 14 , indicating that enzyme digestion of $\mathrm{C}$-terminal lysine residue was more effective in uridine added culture. This result is not consistent with the higher basic variants contents caused by uridine, suggesting that higher basic variants in uridine added culture mainly came from other modifications.

Figure $5 \mathrm{~b}$ showed that other basic variants maintained at a high level in uridine added culture, which reached $25.2 \%$ at day 14 . However, in control culture, other basic variants contents gradually decreased since day 6 , and dropped to $11.8 \%$ at day 14 , which was significantly lower than those in uridine added culture $(p<0.01)$. The contents of other basic variants are of great importance in
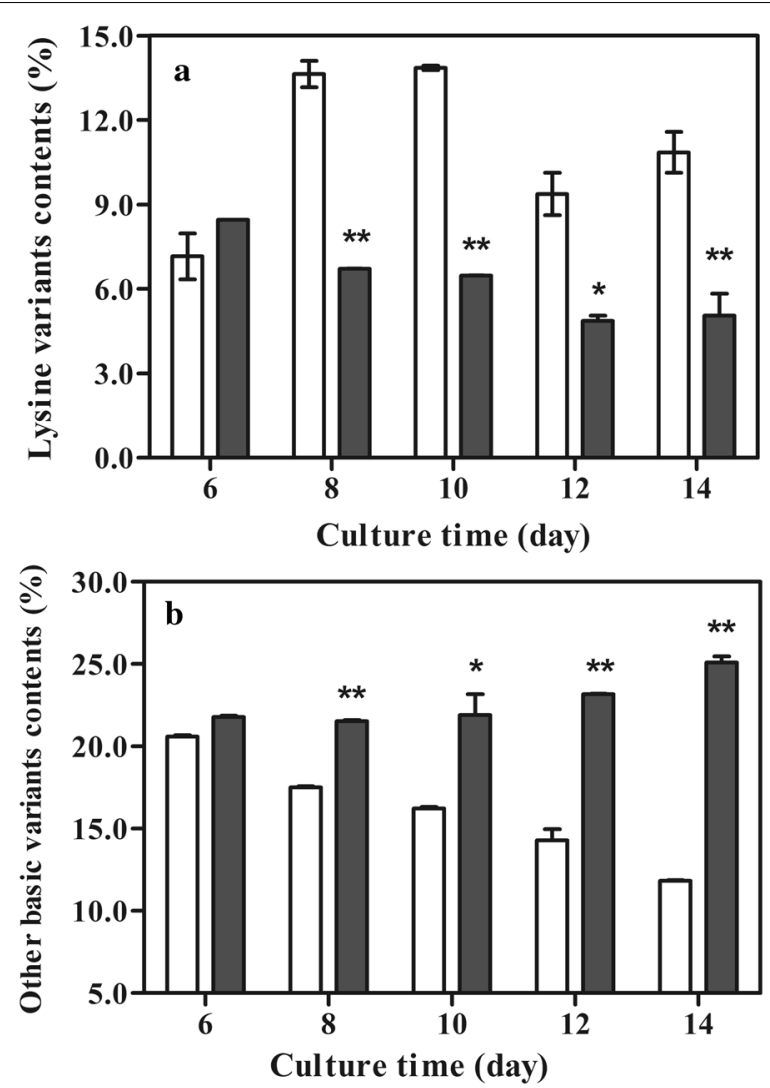

Fig. 5 Profiles of mAb lysine variant level and other basic variant level in different feed medium. a Lysine variant level; $\mathbf{b}$ other basic variant. (White bar) control condition; (shaded bar) uridine added condition. Other basic variant was detected with carboxypeptidase B treatment; lysine variant level was quantified by comparing the basic variant levels obtained from WCX with or without carboxypeptidase B treatment. The error bars indicate the standard deviations from three independent experiments and $p$-values were estimated by two-tailed Student's $t$-test. ${ }^{*} p<0.05$ relative to control; ${ }^{* *} p<0.01$ relative to control

monoclonal production practice in which lysine residues can be removed in purification steps. From this perspective, uridine's negative impacts on basic variants were more considerable for fed-batch culture process development. Other basic variants may caused by proline amidation, which is a further modification followed by lysine cleavage. As C-terminus of the heavy chain usually ends with the $-\mathrm{P}-\mathrm{G}-\mathrm{K}$ (proline-glycine-lysine) sequence, the exposed glycine would be further removed and proline would be amidated after the cleavage of lysine, resulting in the generation of basic variants. Therefore, other basic variants increased as lysine variants decreased may due to proline amidation, and the further characterization work by peptide map is ongoing. 


\section{Discussion}

The study we performed was in fed-batch culture process, and uridine was added into cell culture fluid daily since day 1 at a total concentration of $6 \mathrm{mM}$. To fully understand uridine's effects on mAb's charge heterogeneity, we did further studies to investigate uridine's feed concentration and feed time (Additional files 1,2). We found that uridine's effects on cell growth and mAb's charge variants were related with feed concentration (feed daily since day 1). At $0.6 \mathrm{mM}$ feed concentration, mAb's acidic species decreased from 28.9 to $22.7 \%$, while basic species increased from 22.6 to $23.3 \%$ compared with control condition (Fig. S2 in Additional file 3), which indicated that uridine's effects was weakened under this concentration. What's more, uridine's promotion effect on cell growth was declined obviously (Additional file 4).

Then we feed uridine from day 1 to day 6 , and from day 7 to day 12 at the same total concentration $(6 \mathrm{mM})$. The results showed that feed time would also influence uridine's effects. Feeding uridine in late phase was more beneficial on charge heterogeneity, which made basic species better controlled (Fig. S4 in Additional file 5). In conclusion, uridine's effects on cell growth and charge variants were related with its feed strategy, and these findings can provide more choices for process optimization.

\section{Conclusions}

Our study found uridine's effects on charge variants for the first time. Uridine was beneficial to the maintenance of cell viability, which made IVCC increased by $50 \%$, and the final titer improved by $64 \%$, but the charge variants distribution was quite changed. When adding uridine in feed medium, acidic variants decreased from 28.9 to $20.0 \%$, while the basic increased from 22.6 to $28.7 \%$ at day 14. By further investigation, we found that uridine decreased the level of aggregates and glycation forms, which might be the main cause for the increased basic variant level. Uridine decreased the lysine variants, suggesting that higher basic variant level was caused by other basic variants. Although uridine led to the increase of basic variants, its beneficial effects on cell growth and acidic variants should be well considered in up-stream process developments. Uridine's adding concentration can be further optimized combined with specific process requirements.

\section{Additional files}

Additional file 1: Table S1. Effect of uridine's feed concentration on cell growth and mAb production. Table S2. Effect of uridine's feed time on cell growth and mAb production.

Additional file 2: Fig. S1. Effects of uridine's feed concentration on cell growth and cell viability. a Viable cell density; b cell viability. Blank diamond control cultures; Blank circle $0.6 \mathrm{mM}$ uridine fed; Blank triangle 6 $\mathrm{mM}$ uridine fed; Blank square $30 \mathrm{mM}$ uridine fed. The error bars indicate the standard deviations from three independent experiments.

Additional file 3: Fig. S2. Effects of uridine's feed concentration on mAb charge variation distribution at day 14. a Acidic variant level; b basic variant level; c main variant level. The error bars indicate the standard deviations from three independent experiments.

Additional file 4: Fig. S3. Effects of uridine's feed time on cell growth and cell viability. a Viable cell density; b cell viability. Blank diamond control cultures; Blank triangle feed from day 1 to day 13; Blank square 6 feed from day 1 to day 6 ; Blank circle feed from day 7 to day 12 . The total feed concentrations were $6 \mathrm{mM}$. The error bars indicate the standard deviations from three independent experiments.

Additional file 5: Fig. S4. Effects of uridine's feed time on mAb charge variation distribution at day 14 . The error bars indicate the standard deviations from three independent experiments.

\section{Abbreviations}

mAb: monoclonal antibody; CHO: Chinese hamster ovary; PTMs: posttranslational modifications; $q_{\mathrm{mAb}}$ : specific mAb production rate; IVCC: integral of viable cell concentration with time; PBS: phosphate buffered saline; CEX: cation exchange chromatograophy; SEC: size exclusion chromatograophy; BAC: boronate affinity chromatograophy; VCD: viable cell density.

\section{Authors' contributions}

$\mathrm{HN}$ performed the research experiments and wrote the manuscript. JW helped in the experiments and manuscript writing. ML and MC helped in the experiments. XL, LZ and WST guided both authors during the experiments and manuscript preparation. LF promoted this manuscript. All authors read and approved the final manuscript.

\section{Acknowledgements}

This work was supported by The State Key Laboratory of Bioreactor Engineering, East China University of Science and Technology (ECUST).

\section{Competing interests}

The authors declare that they have no competing interests.

\section{Availability of data and materials}

The datasets supporting the conclusions of this article are included in the main manuscript. The authors promise to provide any missing data on request.

\section{Consent for publication}

Not applicable.

Ethics approval and consent to participate

Not applicable.

Funding

Not applicable. 


\section{Publisher's Note}

Springer Nature remains neutral with regard to jurisdictional claims in published maps and institutional affiliations.

Received: 19 July 2018 Accepted: 17 September 2018

Published online: 26 September 2018

\section{References}

Brorson K, Jia AY (2014) Therapeutic monoclonal antibodies and consistent ends: terminal heterogeneity, detection, and impact on quality. Curr Opin Biotechnol 30:140-146

Chen F, Fan L, Wang J, Zhou Y, Ye Z, Zhao L, Tan W-S (2011) Insight into the roles of hypoxanthine and thydimine on cultivating antibody-producing $\mathrm{CHO}$ cells: cell growth, antibody production and long-term stability. Appl Microbiol Biotechnol 93:169-178. https://doi.org/10.1007/s0025 3-011-3484-z

Dillon T et al (2008) Structural and functional characterization of disulfide isoforms of the human IgG2 subclass. J Biol Chem 283:16206

Gandhi S, Ren D, Xiao G, Bondarenko P, Sloey C, Ricci MS, Krishnan S (2012) Elucidation of degradants in acidic peak of cation exchange chromatography in an IgG1 monoclonal antibody formed on long-term storage in a liquid formulation. Pharm Res 29:209-224. https://doi.org/10.1007/s1109 5-011-0536-0

Gramer MJ et al (2011) Modulation of antibody galactosylation through feeding of uridine, manganese chloride, and galactose. Biotechnol Bioeng 108:1591-1602. https://doi.org/10.1002/bit.23075

Haberger M et al (2014) Assessment of chemical modifications of sites in the CDRs of recombinant antibodies. mAbs 6:327

Hong JK, Lee SM, Kim KY, Lee GM (2014) Effect of sodium butyrate on the assembly, charge variants, and galactosylation of antibody produced in recombinant Chinese hamster ovary cells. Appl Microbiol Biotechnol 98:5417-5425. https://doi.org/10.1007/s00253-014-5596-8

Hossler P et al (2015) Cell culture media supplementation of bioflavonoids for the targeted reduction of acidic species charge variants on recombinant therapeutic proteins. Biotechnol Prog 31:1039-1052. https://doi. org/10.1002/btpr.2095

Jayapal KP, Wlaschin KF, Hu WS, Yap MGS (2007) Recombinant protein therapeutics from $\mathrm{CHO}$ cells -20 years and counting. Chem Eng Prog 103:40-47

KaschakT et al (2011) Characterization of the basic charge variants of a human IgG1: effect of copper concentration in cell culture media. mAbs 3:577-583. https://doi.org/10.4161/mabs.3.6.17959
Khawli LA et al (2010) Charge variants in lgG1: isolation, characterization, in vitro binding properties and pharmacokinetics in rats. mAbs 2:613-624. https://doi.org/10.4161/mabs.2.6.13333

Liu H, Gaza-Bulseco G, Faldu D, Chumsae C, Sun J (2008) Heterogeneity of monoclonal antibodies. J Pharm Sci 97:2426-2447. https://doi. org/10.1002/jps.21180

Luo J, Zhang J, Ren D, Tsai WL, Li F, Amanullah A, Hudson T (2012) Probing of $C$-terminal lysine variation in a recombinant monoclonal antibody production using Chinese hamster ovary cells with chemically defined media. Biotechnol Bioeng 109:2306-2315. https://doi.org/10.1002/ bit. 24510

Siemiatkoski J, Lyubarskaya Y, Houde D, Tep S, Mhatre R (2006) A comparison of three techniques for quantitative carbohydrate analysis used in characterization of therapeutic antibodies. Carbohydr Res 341:410-419. https:// doi.org/10.1016/j.carres.2005.11.024

Sun Y-T, Zhao L, Ye Z, Fan L, Liu X-P, Tan W-S (2013) Development of a fed-batch cultivation for antibody-producing cells based on combined feeding strategy of glucose and galactose. Biochem Eng J 81:126-135. https://doi. org/10.1016/j.bej.2013.10.012

Takagi Y, Kikuchi T, Wada R, Omasa T (2017) The enhancement of antibody concentration and achievement of high cell density $\mathrm{CHO}$ cell cultivation by adding nucleoside. Cytotechnology 69:511-521. https://doi.org/10.1007/ s10616-017-0066-7

Wei B, Berning K, Quan C, Zhang YT (2017) Glycation of antibodies: modification, methods and potential effects on biological functions. mAbs 9:586-594. https://doi.org/10.1080/19420862.2017.1300214

Yan B et al (2009) Succinimide formation at Asn 55 in the complementarity determining region of a recombinant monoclonal antibody $\lg G 1$ heavy chain. J Pharm Sci 98:3509-3521. https://doi.org/10.1002/jps.21655

Yang JM et al (2014) Investigation of the correlation between charge and glycosylation of IgG1 variants by liquid chromatography-mass spectrometry. Anal Biochem 448:82-91. https://doi.org/10.1016/j.ab.2013.11.020

Yoon SK, Kim SH, Lee GM (2003) Effect of low culture temperature on specific productivity and transcription level of anti-4-1BB antibody in recombinant Chinese hamster ovary cells. Biotechnol Prog 19:1383-1386

Zhang T, Bourret J, Cano T (2011) Isolation and characterization of therapeutic antibody charge variants using cation exchange displacement chromatography. J Chromatogr A 1218:5079-5086. https://doi.org/10.1016/j. chroma.2011.05.06

Zhang X, Tang H, Sun YT, Liu X, Tan WS, Fan L (2015) Elucidating the effects of arginine and lysine on a monoclonal antibody C-terminal lysine variation in CHO cell cultures. Appl Microbiol Biotechnol 99:6643-6652. https://doi. org/10.1007/s00253-015-6617-y

\section{Submit your manuscript to a SpringerOpen ${ }^{\circ}$ journal and benefit from:}

- Convenient online submission

- Rigorous peer review

- Open access: articles freely available online

- High visibility within the field

- Retaining the copyright to your article

Submit your next manuscript at $\boldsymbol{\nabla}$ springeropen.com 